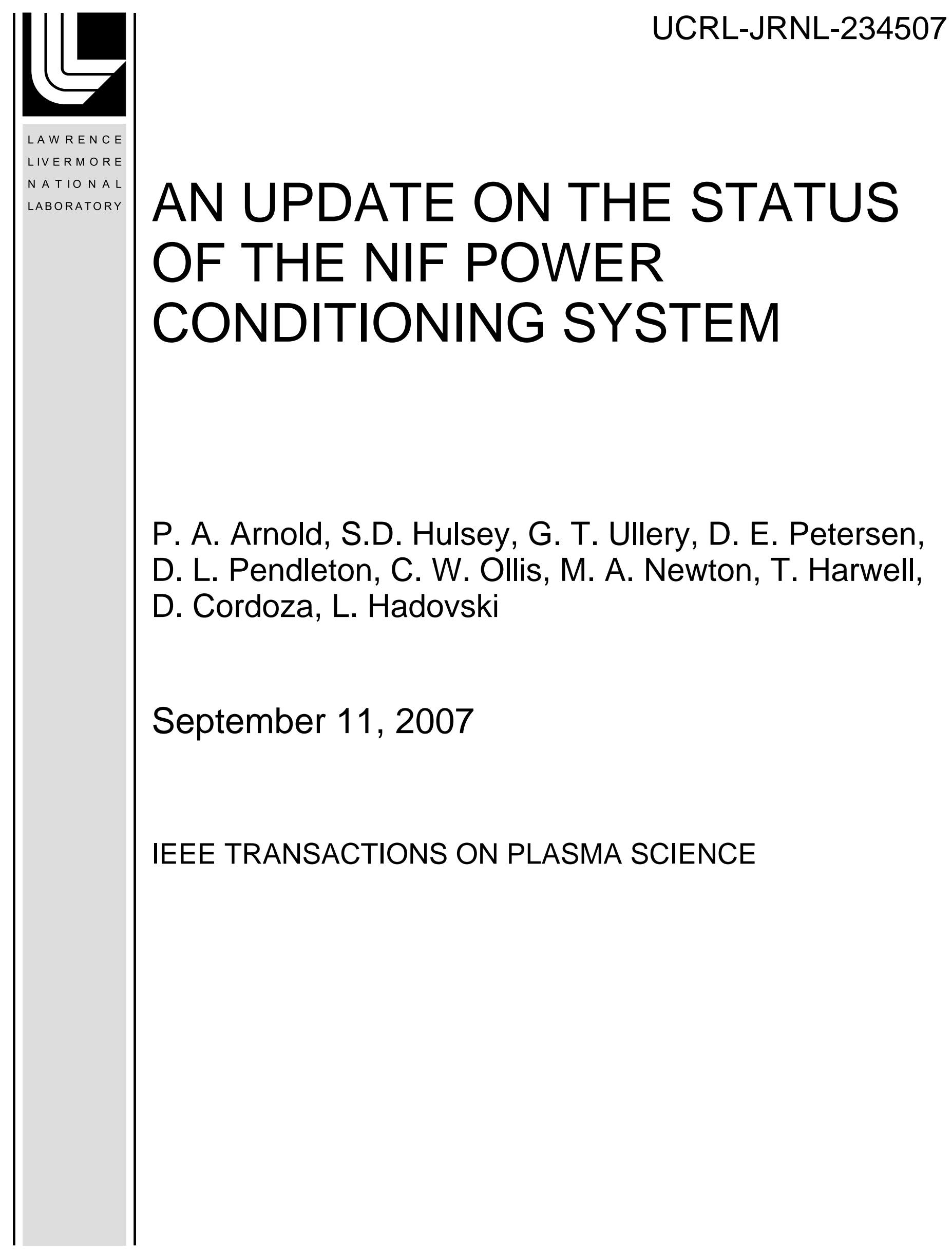


This document was prepared as an account of work sponsored by an agency of the United States government. Neither the United States government nor Lawrence Livermore National Security, LLC, nor any of their employees makes any warranty, expressed or implied, or assumes any legal liability or responsibility for the accuracy, completeness, or usefulness of any information, apparatus, product, or process disclosed, or represents that its use would not infringe privately owned rights. Reference herein to any specific commercial product, process, or service by trade name, trademark, manufacturer, or otherwise does not necessarily constitute or imply its endorsement, recommendation, or favoring by the United States government or Lawrence Livermore National Security, LLC. The views and opinions of authors expressed herein do not necessarily state or reflect those of the United States government or Lawrence Livermore National Security, LLC, and shall not be used for advertising or product endorsement purposes. 


\title{
An Update on the Status of the NIF Power Conditioning System
}

\author{
P. A. Arnold, S. D. Hulsey, G. T. Ullery, D. E. Petersen, D. L. Pendleton, \\ C. W. Ollis, M. A. Newton, T. B. Harwell and L. M. Hadovski
}

\begin{abstract}
The National Ignition Facility (NIF) Power Conditioning System provides the pulsed excitation required to drive flashlamps in the laser's optical amplifiers. Modular in design, each of the 192 Main Energy Storage Modules (MESMs) stores up to $2.2 \mathrm{MJ}$ of electrical energy in its capacitor bank before delivering the energy to 20 pairs of flashlamps in a $400 \mu \mathrm{s}$ pulse (10\% power points). The peak current of each MESM discharge is $0.5 \mathrm{MA}$.

Production, installation, commissioning and operation of the NIF Power Conditioning continue to progress rapidly, with the goals of completing accelerated production and commissioning by early 2008, while maintaining an aggressive operation schedule. To date, more than $97 \%$ of the required modules have been assembled, shipped and installed in the facility, representing more that $380 \mathrm{MJ}$ of stored energy available for driving NIF flashlamps. The MESMs have displayed outstanding reliability during daily, multiple-shift operations.
\end{abstract}

Index Terms - Inertial Confinement Fusion; National Ignition Facility; Power Conditioning.

\section{INTRODUCTION}

The Power Conditioning System of the National Ignition Facility at the Lawrence Livermore National Laboratory (LLNL) is rapidly approaching the end of its multi-year production phase with the ultimate goal of commissioning and operating all elements of the 400 MJ bank by the end of 2007. Module installation, activation and commissioning are progressing in near lockstep with production. Meanwhile, NIF currently relies on more than 180 installed and commissioned modules to support on-going two-shift-per-day laser operations.

To date, more than $97 \%$ of the required modules have been fabricated and installed in the facility. Production rate at Raytheon Technical Services (Chula Vista, CA) is averaging more than 5 modules per month over the last year in order to meet NIF's accelerated installation schedule.

\footnotetext{
Manuscript received September 13, 2007. This work performed under the auspices of the U.S. Department of Energy by the University of California Lawrence Livermore National Laboratory under Contract No. W-7405-Eng-

P. A. Arnold (925-423-8084; e-mail: arnold3@llnl.gov), G. T. Ullery, D. E. Petersen, D. L. Pendelton and M. A. Newton are with Lawrence Livermore National Laboratory, 7000 East Avenue, Livermore, CA, U.S.A.

T. Harwell and L. Hadovski are with Raytheon Technical Services, 1650 Industrial Boulevard, Chula Vista, CA, U.S.A.
} 48.

\section{BACKGROUND}

The National Ignition Facility (NIF) is a laser fusion driver whose design and construction have spanned more than ten years. The stadium-sized facility, funded by the US Department of Energy, has three primary missions: stockpile stewardship, fusion energy research and astrophysics studies.

Conventional facilities work in NIF has ended. The main emphases have now shifted to installing, activating and commissioning laser hardware; completing the implementation and testing of control software; and integrating the hardware and software into a fully operational system with the goal of performing fusion experiments by 2010.

Among the key systems in NIF is the Power Conditioning System (PCS). PCS provides the high-power pulsed excitation required to drive the nearly 8000 xenon flashlamps in the laser's optical amplifiers- the two-pass power amplifier and the four-pass main amplifier. A total of 192 PCS modules will be installed by the end of 2007 to provide the gain for the facility's 192 beams. (Note that there is not a one-to-one correspondence between PCS modules and beamlines.) Each module is capable of storing up to $2.2 \mathrm{MJ}$ of electrical energy before delivering the energy to 20 pairs of flashlamps in a critically damped $400 \mu$ s pulse (10\% power points). The peak current of each Main Energy Storage Module (MESM) discharge exceeds 0.5 MA. Thus, a "system” shot will be characterized by the delivery of $\sim 400 \mathrm{MJ}$ of electrical energy to the flashlamps, with a peak power of $1.25 \mathrm{TW}$ and a total peak current of 100 MA. .,2,3 $^{\text {10 }}$

The modules deployed in NIF represent the culmination of extensive design and development efforts on the parts of groups from LLNL and Sandia National Laboratories, as well as numerous industrial partners, including L-3 Communication (Physics International), Ktech, American Control Engineering, General Atomics, Universal Voltronics, ICAR and Raytheon.

The required quantity of modules and the nature of the module design led to a decision to place the fabrication, initial testing and installation of the system in the hands of an external vendor. These considerations opened the door for vendors with demonstrated expertise with volume production of high-tech hardware in addition to traditional pulsed power vendors. After a competitive bid process the contract was awarded to Raytheon Technical Services of Chula Vista CA, a vendor with a history of production work for the US military, with particular emphasis on large systems for the US Navy. 


\section{REQUIREMENTS}

NIF is intended target shooter, designed to operate three shifts per day, seven days a week and delivering as many as six 1.8 MJ optical pulses per day to targets in the target bay. (This can be augmented by numerous "rod shots" that do not require gain in the main amplifier and power amplifier and, thus, do not require the protracted cooling of amplifier glass between shots.) As such, performance and reliability are paramount. Requirements flow down to the individual systems, with PCS requirements largely derived from and driven by laser goals for performance, lifetime and availability. Top level requirements for the Power Conditioning System are captured in Table 1.

Table 1. PCS System Requirements

\begin{tabular}{|l|l|}
\hline Parameter & Value/Range \\
\hline Number of modules & $\begin{array}{l}192 \text { with potential for } \\
\text { additional expansion }\end{array}$ \\
\hline Nominal energy stored & $400 \mathrm{MJ}$ \\
\hline Output pulsewidth & $400 \mu \mathrm{s}(10 \%$ points $)$ \\
\hline Charge voltage & $24 \mathrm{kV}$ \\
\hline $\begin{array}{l}\text { Shot-to-shot Energy } \\
\text { repeatability }\end{array}$ & $<1 \% \mathrm{rms}$ \\
\hline Temporal energy spread & $\begin{array}{l}<2 \mu \mathrm{s} \text { across all modules } \\
\text { in a capacitor bay }\end{array}$ \\
\hline Minimum Amplifier gain & $5 \% / \mathrm{cm}$ \\
\hline Operational lifetime & 30 years with maintenance \\
\hline Reliability & $>92 \%$ \\
\hline
\end{tabular}

Individual module requirements are, in turn, derived from system requirements with additional requirements based on operational, safety and functional needs of the system. Table 2 delineates primary module and module component requirements. In keeping with NIF's overall architecture employing Line Replaceable Units (LRUs), subcomponents of the modules are intended to be replaced rather than repaired in situ. Subcomponents will, of course, be transported to and repaired in off-line facilities.

Table 2. Individual module/component requirements.

\begin{tabular}{|c|c|c|}
\hline Subsystem & Parameter & Value/Range \\
\hline \multicolumn{3}{|l|}{$\begin{array}{l}\text { Main energy } \\
\text { storage module }\end{array}$} \\
\hline & Capacitance & $\begin{array}{l}6.0 \text { to } 7.2 \mathrm{mF}(20 \\
-24 \text { capacitors) }\end{array}$ \\
\hline & $\begin{array}{l}\text { Nominal charge } \\
\text { voltage }\end{array}$ & $24 \mathrm{kV}$ \\
\hline & $\begin{array}{l}\text { Dwell time at } \\
\text { charge voltage }\end{array}$ & $<15 \mathrm{~s}$ \\
\hline \multicolumn{3}{|c|}{ Reversal } \\
\hline \multicolumn{3}{|l|}{ Main switch } \\
\hline & Peak current & $550 \mathrm{kA}(\max )$ \\
\hline & Action & $67 \mathrm{MJ} / \Omega(\max )$ \\
\hline & $\begin{array}{l}\text { Coulomb } \\
\text { transfer }\end{array}$ & $\begin{array}{l}>280 \mathrm{kC} \text { ( per } \\
\text { refurbishment) }\end{array}$ \\
\hline
\end{tabular}

\begin{tabular}{|c|c|c|}
\hline "Subsystem & Parameter & $\begin{array}{l}\text { Value/Range } \\
\end{array}$ \\
\hline \multicolumn{3}{|l|}{ Power supplies } \\
\hline & Charge voltage & $\begin{array}{l}24 \mathrm{kV} \text { (nominal), } \\
26 \mathrm{kV} \text { (max) }\end{array}$ \\
\hline & Charge Rate & $25 \mathrm{~kJ} / \mathrm{s}$ \\
\hline & Regulation & $0.05 \%$ \\
\hline \multicolumn{3}{|l|}{$\begin{array}{l}\text { Pre- } \\
\text { ionization/Lamp } \\
\text { Check circuit }\end{array}$} \\
\hline & Capacitance & $130 \mu \mathrm{F}$ \\
\hline & Charge voltage & $26 \mathrm{kV}$ \\
\hline Dump circuits & Discharge time & $\begin{array}{l}<10 \text { seconds (with } \\
\text { redundant dumps) }\end{array}$ \\
\hline \multicolumn{3}{|l|}{ Capacitors } \\
\hline & Capacitance & $290 \mu \mathrm{F},-0+10 \%$ \\
\hline & $\begin{array}{l}\text { Equivalent Series } \\
\text { Resistance (ESR) }\end{array}$ & $<15 \mathrm{~m} \Omega$ \\
\hline
\end{tabular}

\section{FUNCTIONAL DESCRIPTION}

NIF is organized into multiple sub-groupings. The facility comprises two laser bays, each with 96 beams. Each laser bay includes 2 clusters of 48 beams. In turn, each cluster is composed of 6 bundles, with the bundle representing the fundamental NIF organization unit, the primal cell whose functionality-both hardware and software-is replicated 24 times throughout the facility. A power conditioning bundle is a group of eight main energy storage modules, the number required to drive flashlamps for single bundle of laser beams. Each bundle of power conditioning units has all the required controls hardware and software, utilities and other elements of the infrastructure required to operate as a completely separate and autonomous unit. (While it is possible to operate a subset of a bundle, the emphasis is on operating this grouping as a fundamental unit.)

MESMs occupy four independent $1150 \mathrm{~m}^{2}$ capacitor bays in the facility, with each supporting a given cluster (i.e., 48 beamlines). Each capacitor bay nominally houses 6 bundles/48 power conditioning modules. Provisions have been made for an additional module in each bundle should future power requirements dictate additional optical energy. (The additional module would provide electrical energy for the flashlamps required to excite an extra pair of laser slabs in the power amplifier section for each beam.) One of three completed capacitor bays is depicted in Figure 1.

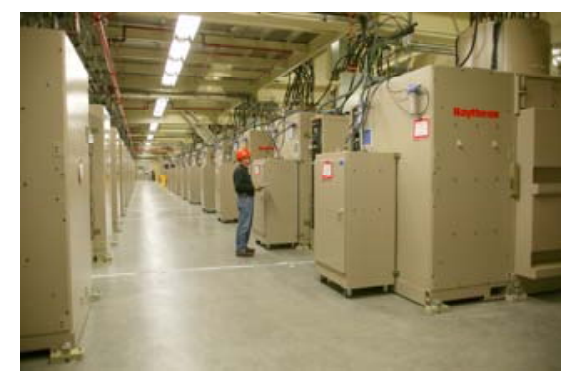

Figure 1. Completed Capacitor Bay with 48 modules, capable of storing $\sim 100$ MJ of electrical energy for flashlamps. 
The MESM design is the latest iteration in the evolution of flashlamp drivers deployed in laser systems at LLNL, including Shiva, Nova and Beamlet. The general direction has been one of reduction of the number of components and an increase in energy and energy density, largely driven by requirements for increased reliability and reduced costs. By following this strategy and employing innovative hardware, including but not limited to self-healing, high energy-density capacitors, a single main switch and commercial, underground residential distribution (URD) cable for transmission of pulses from modules to flashlamps, NIF has been able to drive the cost of the system down to $\sim \$ 0.20 / \mathrm{J}$. Comparative data for NIF and its predecessors at LLNL are captured in Figure 2.

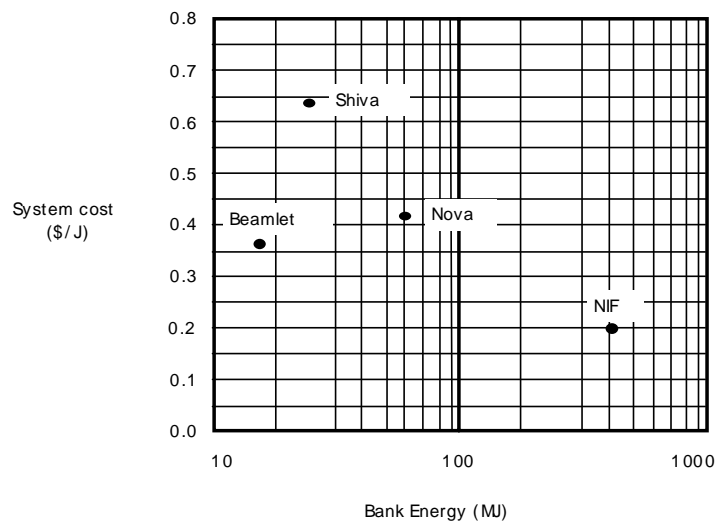

Figure 2. Per-unit cost of stored energy for LLNL historical and present flashlamp drivers (in today's dollars).

As shown in Table 3, components in the MESM are required to be both long-lived and reliable in order to achieve the required 30 year life for the facility. Experimental data indicate that these requirements are achievable, even for high voltage/high energy density components. As an example, energy storage capacitors must be capable of achieving a minimum of 20,000 shots while rigorous life-testing shows that 50,000 shots are consistently achievable.

Table 3. Lifetime requirements for major components in the PCS MESM.

\begin{tabular}{|l|l|l|}
\hline Component & $\begin{array}{l}\text { Required } \\
\text { lifetime/no. } \\
\text { shots }\end{array}$ & Validated life \\
\hline Capacitors & 20,000 shots & $>50,000$ shots \\
\hline Main switch & $\begin{array}{l}2000 \text { shots }(280 \\
\text { kC) }\end{array}$ & $\begin{array}{l}\text { Rebuild at } 2000 \\
\text { shots }\end{array}$ \\
\hline $\begin{array}{l}\text { Main Switch } \\
\text { Trigger }\end{array}$ & 20,000 & 100,000 shots \\
\hline
\end{tabular}

A simplified schematic of a MESM is depicted in Figure 3. Energy is stored in $20-24$ capacitors with the module capacitance ranging from 6 to $7.2 \mathrm{mF}$. Capacitors employ metalized-film technology with self-healing capabilities to achieve required lifetime and reliability. These capacitors are charged by a pair of switching power supplies, with the pair capable of charging the bank to $24 \mathrm{kV}$ in just over 1 minute. Each capacitor is equipped with and protected from the effects of internal faults by a potted, stainless steel damping element (nominally $9 \mu \mathrm{H}$ and $25 \mathrm{~m} \Omega$ ). A damping element is capable of maintaining its mechanical integrity through a capacitor fault and subsequent discharging of the full bank into the shorted capacitor, but must be replaced along with the shorted capacitor after the event.

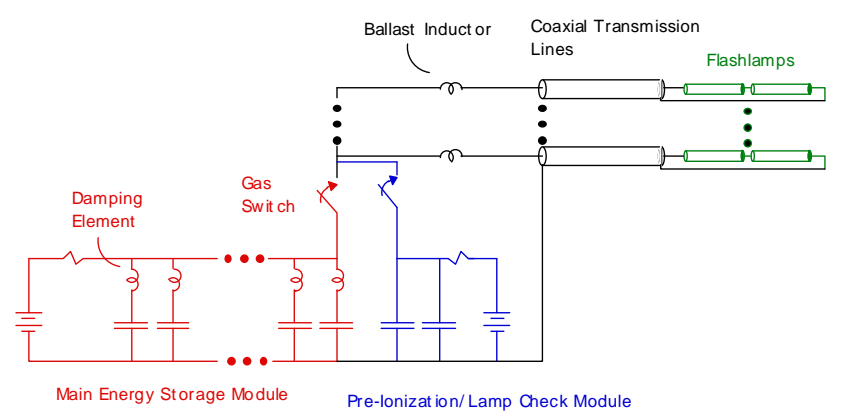

Figure 3. Simplified schematic of the PCS Main Energy Storage Module

The MESM main switch is a spark gap pressurized with clean, dry air. Offline experiments have shown that the spark gaps are capable of transferring $\sim 280 \mathrm{kC}$ and operating for more than 2000 shots before the eroded graphite electrodes must be replaced. However, the spark plug used to trigger the switch is replaced twice as often. The pressure setpoint for a switch is determined by the amount of charge that has been conducted by the switch. (Switches are operated at approximately $50 \%$ of their self-breakdown voltage to reduce pre-fires, yet trigger reliably.) Erosion and gas breakdown byproducts are swept from the switch after each pulse by means of an air purge. Particulate matter is captured in a filter for future disposal. Ozone is swept into an exhaust system. The trigger for the main switch is provided by a pulse generator capable of delivering a pulse with a peak voltage of more than $110 \mathrm{kV}$ to the spark gap trigger embedded in the wall of the switch. Figure 4 captures a discharge event in the main switch.

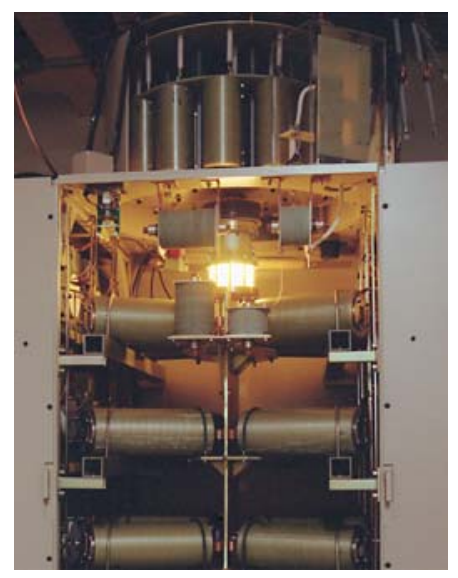

Figure 4. MESM discharge. Damping elements are visible below the switch. Ballast inductors are located above the switch in the "top hat." 
Wound from $6 \mathrm{~mm}$ diameter copper wire, the ballast inductors are potted and then embedded in a fiberglass cylinder. The coils for a given module are chosen from four sub-types, each with a different inductance. The ballast inductors are used to set the pulsewidth of the output pulse and must compensate for varying cable lengths between the module and flashlamps. Each module is connected to the flashlamp cassette via 21 concentric neutral URD cables, with 20 connecting directly to flashlamps and a single cable providing a well-defined, low-impedance path for reflector fault currents. (As intimated, employing URD instead of RG220 substantially reduced cable acquisition costs. In fact, the program saved over $\$ 1 \mathrm{M}$ for the more than $150 \mathrm{~km}$ of URD that were purchased and installed.) Cable lengths range from 20 to 57 meters, depending on the distance from the module to the flashlamps it drives. The current of each cable is monitored on each shot to provide necessary feedback on module performance and flashlamp health. While MESMs correspond to flashlamps within a given bundle, the output of a given module may drive flashlamps in both the main amplifier and power amplifier.

Unlike the pulsed power system in Nova, NIF's predecessor, the MESMs have an autonomous, self-contained pre-ionization/lamp check (PILC) system. A separate $26 \mathrm{kV}$ power supply and a pair of energy storage capacitors provide the energy that is switched through a dedicated spark gap for initiating the ionization process in the flashlamps approximately $300 \mu$ s before the main pulse. The preionization pulse stores and delivers energy equivalent to $~ 5 \%$ of that which is stored in the main bank. A lamp check pulse is applied after each main shot to verify that the flashlamps have survived the main discharge and are ready for the next shot. Erosion in the PILC spark gap is virtually non-existent so this switch operates at a constant pressure throughout its life.

\section{CONTROLS}

A NIF "shot" is coordinated from the facility's main control room. A (human) shot director leads a small team of operators, including one who is responsible for PCS. The PCS operator is responsible for the manually setting participation of modules, following checklists during pre-shot countdown, starting software, monitoring top-level system performance via top-level and lower level Graphical User Interfaces (GUIs), and interacting with the shot director before and during and after shot sequences. While the human operator is currently indispensable, the complexity of the PCS, specifically, and NIF, in general, dictates a computer control system to handle the intricacies and precision of the sequence.

NIF utilizes a multi-tiered control system consisting of high-level supervisory controls and mid-level front end processors which interface to the hardware. PCS then incorporates a third layer of computer control through embedded controller, with one controller housed in each module.
In the NIF supervisory layer, a single, overarching NIF Shot supervisor orchestrates a shot sequence, providing coordination of all subsystem shot supervisors including that of the Power Conditioning System. The PCS Shot Supervisor coordinates the actions of all 24 PCS bundle Logical Control Units (LCUs). It also provides a single high-level GUI for overall PCS shot control, displayed at the PCS console in the NIF control room. Each LCU provides all mid- and low-level GUIs for its bundle and coordinates the actions of the eight PCS modules per bundle through front end processors. For the PCS, the Front End Processor Layer consists of one physical front end processor per bundle running eight instances of the FEP code, one for each PCS module. In turn, each module is equipped with a Pentium-based embedded controller which provides all I/O to internal PCS devices. In particular, the embedded controller is responsible for: AC power distribution; controlling and regulating the air supplied to the output switches; controlling and monitoring dump relays; acquiring and temporarily storing shot data; controlling trigger generators, $\mathrm{HV}$ power supplies and current monitors; aborting when charge time limits are exceeded; and interfacing with the higher level components of the control system.

A typical shot sequence (from a PCS standpoint) is as follows: The operator, under the direction of the shot director, chooses the modules that will participate in the shot, using the top-level GUI interface. Software, aware of the status of each main switch and its historical charge transfer, issues commands that set the pressure in the gas chassis and, ultimately, the main switch. At the appropriate time (approximately 1 minute prior to the propagation of the laser) software issues commands that lead to the charging of the main bank and PILC bank and the charging of the spark gap triggers. (The system is monitored for pre-fires at all times.) At a prescribed time the NIF integrated timing system provides triggers for the switches, thus delivering the stored energy to the flashlamps. Once timing system has issued triggers for the PILC and main switches, the system acquires the shot data from the embedded controller, performs postshot waveform analysis and controls the lamp check shot as well as the purge cycles for the two spark gaps residing in each module.

\section{SAFETY}

Personnel and equipment safety is of utmost importance. MESMs, with their heavy (4.75 mm thick) steel walls, are designed to contain shrapnel generated during a fault. Pressure relief has been incorporated into the design as well, with large vents built into both access doors. (Note that any shrapnel following the serpentine path of the gas will experience at least three energy-depleting caroms before embedding themselves in a block of soft pine.) Walls of the capacitor bays are encased in heavy plywood for additional protection. In addition, the capacitor bays are swept prior to charging and remain unoccupied during shots. Doors are interlocked and tied into a NIF-wide safety interlock system (SIS). The SIS crashes the system, dumping stored energy 
should individuals break the interlocks or should the PCS operator identify an unsafe situation.

Given the amount of energy stored in the modules and the potential for shock or electrocution, lock-out tag-out (LOTO) and "safing" procedures are strictly enforced and are driven by detailed procedures. In addition, all capacitor bay toolboxes are "shadowed" to indicate when hand tools are out of place, to prevent tools from inadvertently being left in a module.

\section{PRODUCTION}

Raytheon Technical Services has served as the system integrator for the vast majority of the PCS modules. As such, Raytheon incorporates various components from their subcontractors, along with government furnished equipment purchased, tested and delivered by LLNL, into complete assemblies that are fully tested before they are shipped to LLNL.

A key element of this integration strategy is random selection of high power components for destructive and/or life testing. As an example, sample inductors and damping elements are routinely sectioned to verify uniformity in potting and winding. Capacitors are pulled from lots for lifetesting (20,000 charge/discharge cycles), while all capacitors experience 500 full-power charge/discharge cycles before being incorporated into a module.

Modules, fully tested at Raytheon, are partially disassembled, loaded onto trucks and shipped to LLNL, where they are installed and re-tested. As part of the cooperative agreement between LLNL and Raytheon, Raytheon participates in the installation and activation of the transported units.

\section{OPERATIONAL STATUS}

Since January 2007, NIF has been operating three shifts per day. Two shifts are dedicated to laser operations, i.e., actual firing of the laser system and propagation of beams. A single shift is dedicated to installing, activating and maintaining equipment. From a PCS standpoint this single shift represents the time when modules are installed and activated, commissioning takes place and the period when problems encountered during operations are addressed. Module activation and commissioning are complex, multi-day processes that exercise all aspects of unit operation, ensuring that all requirements are met before the hardware is turned over to NIF Operations. In particular, each module is checked for proper operation of its safety system including its interface to the SIS and redundant internal dumps, its communication and data acquisition systems, performance of the power supplies, main and PILC switches,

At this point in time, three of the four capacitor bays are operational, with the commissioned modules being used to support shot operations. A fourth bay is being populated at an accelerated rate with the module fabricator/integrator, Raytheon Technical Services, producing and delivering an average of seven modules per month.

To date, PCS has achieved and maintained outstanding reliability, achieving greater than 95\% availability for shots.
Tens of thousands of modules (main, pre-ionization and lamp check) pulses have been accumulated as part of module system activation, commissioning and operations. The system has been demonstrated to be extremely noise-immune, a feature attributable to well-planned and implemented grounded and shielding and an effective use of optical isolators and fiber optic coupling.

\section{FUTURE WORK}

Over the next few months, the mission of the power conditioning group will be to complete the installation, activation and commissioning of the few remaining modules. Completion of module commissioning will mark the shift to an emphasis on the development and training of a sustaining maintenance and operations organization. Already, preparation of training documentation is being prepared in large volumes and operations workers are being trained to take on the varied tasks that will occupy them once the engineering team takes a less prominent role.

\section{CONCLUSION}

The Power Conditioning System at the National Ignition Facility is on a path for module production and final system commissioning to be completed in early 2008. The entire facility is scheduled to be completed in 2009 with 2010 bringing a campaign to achieve fusion using all 192 beams.

\section{REFERENCES}

[1] M. Newton, NIF Amplifier Power Conditioning System (PCS) Design Basis Document, LLNL Internal Document, June 2002.

[2] Mark A. Newton, et al., NIF Amplifier Power Conditioning System (PCS) Hazard Analysis and Safety Implementation Plan, LLNL Internal Document, UCRL-MA-150514, Oct. 1, 2002.

[3] M. Newton, et al., Main Amplifier Power Conditioning for the NIF, LLNL Internal Document, UCRL-LR-105821-99-1. 